\title{
Synthesis and Characterization of Aliphatic Polyesters from Glycerol, by-Product of Biodiesel Production, and Adipic Acid
}

Michel de Meireles Brioude ${ }^{\text {a }}$, Danilo Hansen Guimarães ${ }^{\text {a }}$ Raigenis da Paz Fiúza a,

\author{
Luis Antônio Sanches de Almeida Prado ${ }^{\mathrm{b}}$, Jaime Soares Boaventura a, Nadia Mamede Joséa* \\ aPrograma de Pós-graduação de Engenharia Química, Instituto de Química, \\ Universidade Federal da Bahia, Campus de Ondina, 40170-290 Salvador - BA, Brazil \\ ${ }^{\mathrm{b}}$ Institute of Polymer and Composites, Technische Universität Hamburg, Harburg
}

Received: December 15, 2006; Revised: November 21, 2007

\begin{abstract}
In the present work, polyesters were prepared from the polycondensation between glycerol and adipic acid using dibutyltin dilaurate as catalyst. Three glycerol: adipic acid molar ratio were used for the bulk polymerization namely: 2:2; $2: 3$ and 2:4. FTIR confirmed the esterification of glycerol by the acid for all the polymers. DSC and XRD indicated no crystallinity for all the polymers. The morphology of the materials are characterized by globular structure, which may suggest compositional fluctuations throughout the samples.
\end{abstract}

Keywords: polyester, glycerol, biodiesel

\section{Introduction}

In the past decades, the development of biomaterials received a great deal of attention. The first material derived from biological/ natural sources is cellulose acetate, which is actually a biodegradable thermoplastic with many applications which includes reverse osmosis membranes ${ }^{1}$. The development of the "green" composites based on vegetable fibres (juta, sisal among others) represent a new step into the use of renewable sources for engineering applications ${ }^{2}$.

Recently the use of vegetal oils to produce monomers tailored for the synthesis of new polymers became a new and promising issue for the development of new materials with reduced cost production and interesting properties ${ }^{3,4}$. Not only the manufacturing of thermoplastics and duromers (thermosets) may benefit from the use of these oils, but also the production of alternative fuels as renewable sources of energy. In this context, the development of new fuels (like the biodiesel) and other products derived from the ricinus oil (castor oil) seems to be very promising ${ }^{5-7}$.

Since bio-diesel is a renewable and environmentally friendly fuel, its production has been encouraged by the Brazilian government ${ }^{7}$. The ricinus oil is an interesting precursor for biodiesel production. Ricinus can be grown up in the arid north-western regions of Brazil, therefore Ricinus plants may become an income for rural population. As a result, 1 employee per 2 hectares may be contracted. The ricinus oil production is about $1 \mathrm{t} / \mathrm{ha}^{9}$.

During the cracking/processing of castor oil, huge amounts (30 wt. (\%)) of glycerol are obtained as by-product ${ }^{10}$. Therefore, the development of new materials derived from the glycerol may contribute to make the production of bio-diesel even more attractive from the economical and technological point of view ${ }^{11,12}$. In this context, we purpose the use of glycerol as monomer for the synthesis of aromatic and/or aliphatic polyesters ${ }^{13}$ with potential applications as membranes, additives for polyurethanes among others ${ }^{14}$.

\section{Experimental}

The starting materials were adipic acid, dibutyltin dilaurate (10 wt. (\%) in hexanes) and glycerol were purchased from Vetec, Sigma-Aldrich and Synth, respectively.
For the polymerization process, glycerol and adipic acid were mixed in a three-necked round-bottomed flask equipped with a contact thermometer and a Claisen-condenser. The mixture was heated up to $100{ }^{\circ} \mathrm{C}$ under constant stirring. After the homogenisation of the mixture, the dibutyltin dilaurate was added and the temperature was increased up to $150^{\circ} \mathrm{C}$. As the polymerisation proceeded, the water produced during the reaction was distilled off and removed by the condenser. The glycerol/adipic acid molar ratio was varied in order to obtain polymers with different properties. The catalyst amount was kept constant at $0.15 \%$ (weight percentage) in relation to the total mass of monomers. The formulations used for the preparation of the poly(glycerol adipate) polymers are summarized in Table 1. For the sake of simplicity, these samples were coded as POLA.

The polymers were obtained as resinous solids and were dried under vacuum at $50{ }^{\circ} \mathrm{C}$ for at least 48 hours.

Powder X ray data for structural analysis were collected on a Shimadzu XRD-600 diffractometer, with $\mathrm{Cu}-\mathrm{K} \alpha$ radiation $(\lambda=1.54 \AA)$, $30 \mathrm{kV}$ potential and $20 \mathrm{~mA}$ current from 5 to 80 degrees.

The infra-red spectra were recorded on a Spectrum One (Perkin Elmer) instrument in the range of 4000 to $500 \mathrm{~cm}^{-1}$ and the samples were analyzed as fine films, aiming at confirming the efficiency of the glycerol esterification process.

The thermal behavior of the polyesters was evaluated by a TGA/DTA 851 (Metler Toledo) thermo-balance. The samples were heated from 25 up to $1000{ }^{\circ} \mathrm{C}$ under $\mathrm{N}_{2}$ flow using a heating rate of $20^{\circ} \mathrm{C} / \mathrm{min}$, and on a DSC 60 (Shimadzu) calorimeter, using a heating rate of $20^{\circ} \mathrm{C} / \mathrm{min}$ from room temperature up to $600{ }^{\circ} \mathrm{C}$.

The morphological analysis were carried out using a SS 550 Scanning Electron Microscope (Shimadzu). The acceleration voltage was $7 \mathrm{kV}$ and the samples were sputtered with gold prior to the analysis.

\section{Results and Discussions}

\subsection{Polymerisation reaction}

The polyesters were produced through polycondensation polymerisation reactions between adipic acid and glycerol, as illustrated by Equation 1: 


$$
\begin{aligned}
& \mathrm{H} \\
& \mathrm{H}-\mathrm{C}-\mathrm{OH} \quad \mathrm{O} \quad \mathrm{H} \quad \mathrm{H} \quad \mathrm{H} \quad \mathrm{H}
\end{aligned}
$$

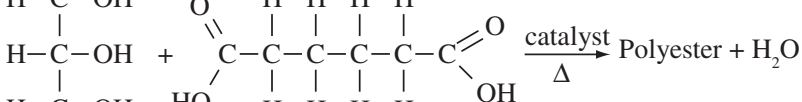

$$
\begin{aligned}
& \begin{array}{cccccc}
\mathrm{H}-\underset{\mathrm{I}}{\mathrm{C}}-\mathrm{OH} & \mathrm{HO} & \mathrm{H} & \mathrm{H} & \mathrm{H} & \mathrm{H} \\
\mathrm{H} & & & & & \\
\end{array} \\
& \text { Glycerol Adípic acid }
\end{aligned}
$$

Table 1. Composition of the polyesters prepared in the present work.

\begin{tabular}{lc}
\hline Sample & Molar ratio (glycerol/adipic acid) \\
\hline POLA I & $1: 1$ \\
POLA II & $1: 1,5$ \\
POLA III & $1: 2$ \\
\hline
\end{tabular}

Since glycerol has three-OH groups, the formation of ramified and/or cross-linked structures can be postulated. The cross-linking degree is determined by the composition of the initial formulation. Highly cross-linked polyesters derived from glycerol and adipic acid is expected to be produced, if 2 mols of glycerol were fully esterified by 3 mols of adipic acid. Therefore, assuming the esterifcation reaction was complete, the polyester POLA II should present the highest cross-linking density of all the polymers prepared in the present work. The polymers POLAI and POLAIII have excess of $-\mathrm{OH}$ and $-\mathrm{COOH}$ functional groups, respectively. Hence, the structures of these materials should contain more branches.

The final structure of the networks does not depend solely on the composition, but also on the changes of the viscosity during the reaction ${ }^{15}$. Since the adipic acid is a solid material, the viscosity of the polymer reactions of mixtures containing higher amounts of adipic acid (POLA II and POLA III) should be higher than that obtained from mixtures having higher amounts of glycerol (POLA I). Since all the polymerization reactions were carried out without any solvent; the viscosity of the reaction media might be very high. In this case, the conversion could be hindered by the restricted diffusion of the monomers in the high viscous polymer dispersion. The high conversion could be guaranteed by removing the water produced during the polymerisation process. The removal of the water shifts the equilibrium to product generation; therefore, the formation of a polymer with higher molecular weight can be favoured.

In fact, the polymers were obtained as resinous materials as shown in Figure 1.

\subsection{Characterization of the polyesters}

\subsection{1. $\mathrm{X}$ ray powder diffraction}

The $\mathrm{X}$ ray diffractograms (Figure 2) showed a broad peak at $2 \theta=20^{\circ}$. This peak is associated to the intra-chain segments distance of $0.45 \mathrm{~nm}$ (determined using the Bragg's law) ${ }^{16}$. Since the intensity increased for the polyester containing higher amounts of adipic acid, it can be suggested that the excess of $-\mathrm{COOH}$ group favoured some mesomorphic (or crystalline) organization of the polyester chains.

\subsubsection{Infrared spectroscopy (FTIR)}

The infrared spectra of the polyesters POLA and of the adipic acid are shown in Figure 3. The esterification of glycerol is confirmed by the presence of the bands at $1739 \mathrm{~cm}^{-1} ; 1134$ and $1118 \mathrm{~cm}^{-1}$; and 1080 and $1064 \mathrm{~cm}^{-1}$, which can be assigned to the ester groups. The band at $1711 \mathrm{~cm}^{-1}$ is indicative of the presence of un-reacted $-\mathrm{COOH}^{17,18}$. The intensity of this band increases proportionally to the adipic acid content in the polymer. The assignment of the absorption bands is summarized in Table 2.

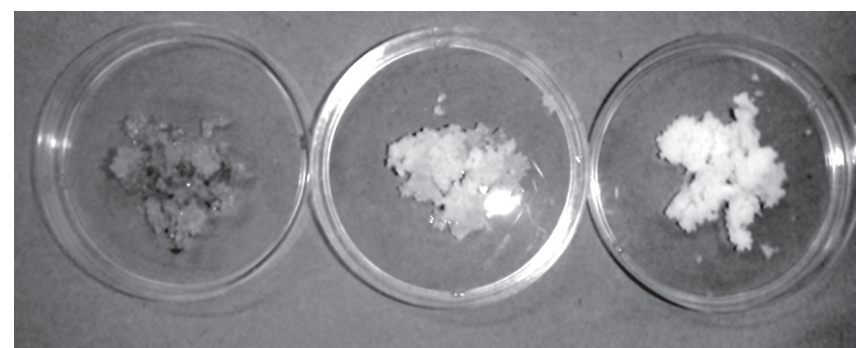

(a)

(b)

(c)

Figure 1. Photograph of the polymers a) POLA I; b) POLA II; and c) POLA III.

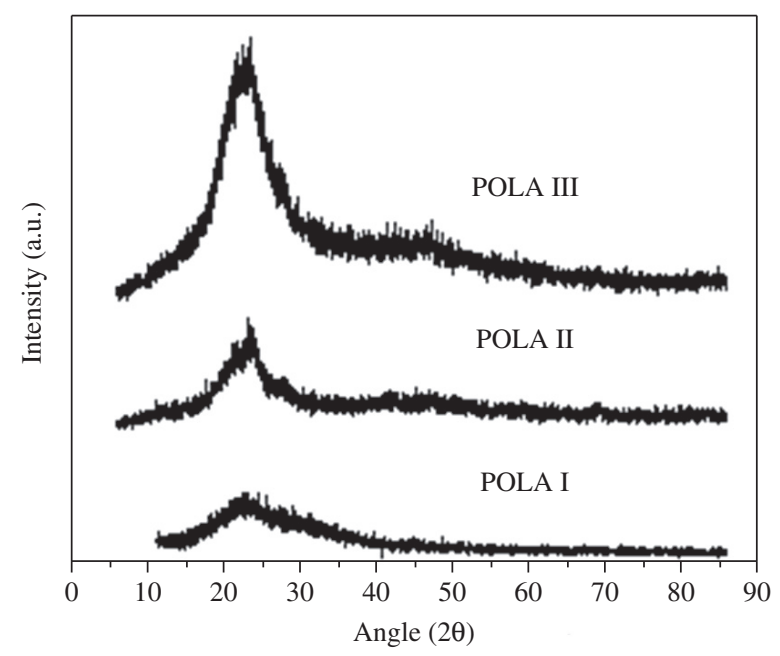

Figure 2. X ray diffractograms of POLA I, POLA II and POLA III.

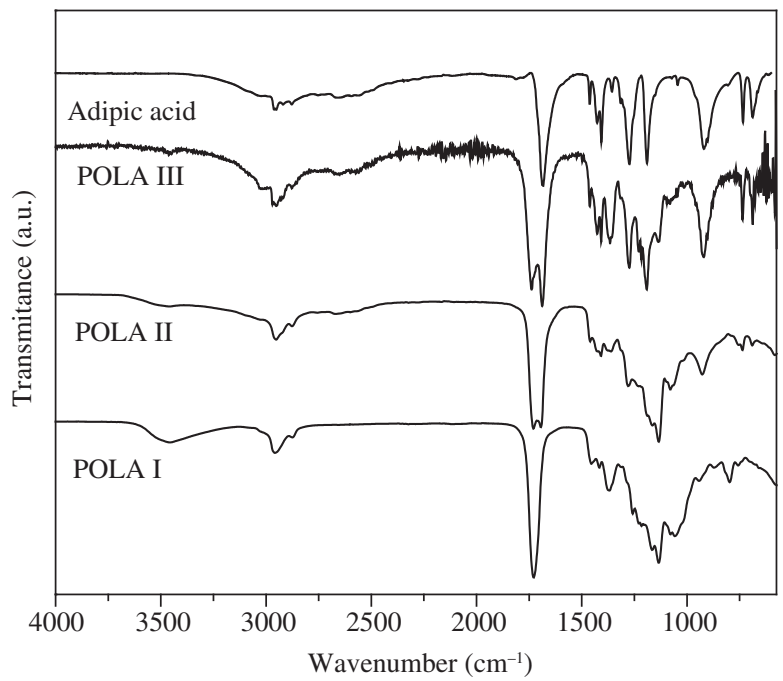

Figure 3. Infra-red spectra from POLA series.

Table 2. FTIR analysis of the POLA polymers ${ }^{16,17}$.

\begin{tabular}{cl}
\hline Wavenumber $\left(\mathrm{cm}^{-1}\right)$ & \multicolumn{1}{c}{ Assignment $^{\mathrm{a}}$} \\
\hline $3300-2500$ & $\mathrm{v}(\mathrm{O}-\mathrm{H})_{\text {alcohol, carboxylic acid }}$ \\
$2950-2932-2855$ & $\mathrm{v}(\mathrm{C}-\mathrm{H})_{\text {alliphatic }}$ \\
1720 & $\mathrm{v}(\mathrm{C}=\mathrm{O})_{\text {ester }}$ \\
1711 & $v(\mathrm{C}=\mathrm{O})_{\text {carboxylic acid dimmer }}$ (free adipic acid) \\
$1439-1371$ & $\delta(\mathrm{C}-\mathrm{H})_{\text {methyl }}$ \\
1215 & $\delta(\mathrm{C}-\mathrm{C})_{\text {ester }}$ \\
\hline
\end{tabular}

${ }^{\mathrm{a}} \mathrm{v}$ : strechting, $\delta$ : bending. 


\subsubsection{Evaluation of the thermal stability}

The thermal stability of the POLA polyester was evaluated by thermogravimetric analysis (TGA). As can be seen in Figure 6a, the decomposition patterns of the POLA polymers present two steps. At temperatures below $100{ }^{\circ} \mathrm{C}, 2 \%$ of weight loss can probably be attributed to the volatilization of low molecular weight compounds (e.g. adsorbed water) and post-curing processes. The degradation of the polyester chain took place at temperatures higher than $300{ }^{\circ} \mathrm{C}$, as observed for many aliphatic polyesters ${ }^{19-22}$. The main degradation step occurred at $\sim 300$ to $485{ }^{\circ} \mathrm{C}$, with a weight loss in the range of 96 to $98 \%$. The chain scission takes place via transfer of the $\mathrm{H}$ (in the $\beta$ position to the oxygen atoms of esterified $-\mathrm{OH}$ groups of the glycerol), followed by cleavage of the $\mathrm{C}-\mathrm{C}$ bond of the glycerol moiety, yielding an alkene and free carboxylic acid as illustrated by the Figure 4.

In spite of the structural complexity, which is expected for the poly(glycerol adipate)s POLA I, II and III; there will be always an hydrogen atom in the suitable configuration for the occurrence of the scission described in Figure 4. Figure 5 detaches the $\mathrm{H}_{\beta}$ of the monoesterified and the di-esterified moieties of the POLA polymers. It is clearly demonstrated here that, there will be always at least one $\mathrm{H}_{\beta}$ for all the isomers, therefore, all the networks prepared in this work should have very similar thermal stability.

In fact, the DTG curves of all polymers prepared in this work (Figure $6 b$ ) are very similar, on account of the presence of $\mathrm{H}_{\beta}$ in all the networks.

\subsubsection{Analysis of the thermal behavior}

The DSC curves of the POLA polymers are shown in Figure 7. The DSC results supported the conclusions drawn from the TGA and DTG. The evaporation and degradation processes could be identified

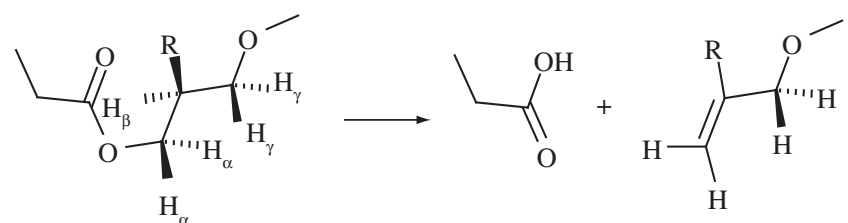

Figure 4. Degradation mechanism proposed for aliphatic polyesters $(\mathrm{R}=-\mathrm{OH}$ or an esterified alcohol group) (adapted from ref. 20).<smiles>[R6][C@H](O)[C@H](C)O</smiles>

(a)

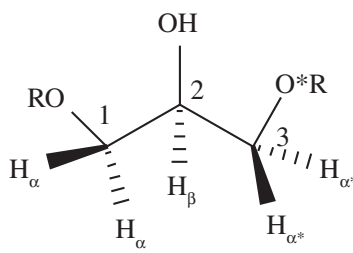

(c)

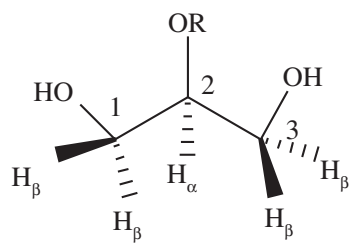

(b)

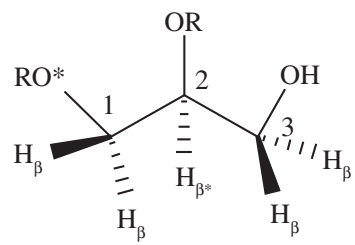

(d)
Figure 5. Mono- and di-esterified moieties of the POLA polymers. (RO and OR represent esterified hydroxyl groups, and $\mathrm{HO}$ and $\mathrm{OH}$ represents the non-esterified hydroxyl groups. The asterisk at the $\mathrm{O}$ atoms serves to distinguish between the two esterified hydroxyl groups and to identify prompter the $H \beta^{\prime}$ s). a) 1-substitued (or 3-substituted) moiety; b) 2-substituted moiety; c) 1,3-disubstituted moiety; and d) 1,2-disubstituted moiety. as peaks associated to two endothermic processes in the intervals between $25-100$ and $390-470{ }^{\circ} \mathrm{C}$. Since no melting peaks could be identified in the DSC curves, these polyesters can be regarded as amorphous materials.

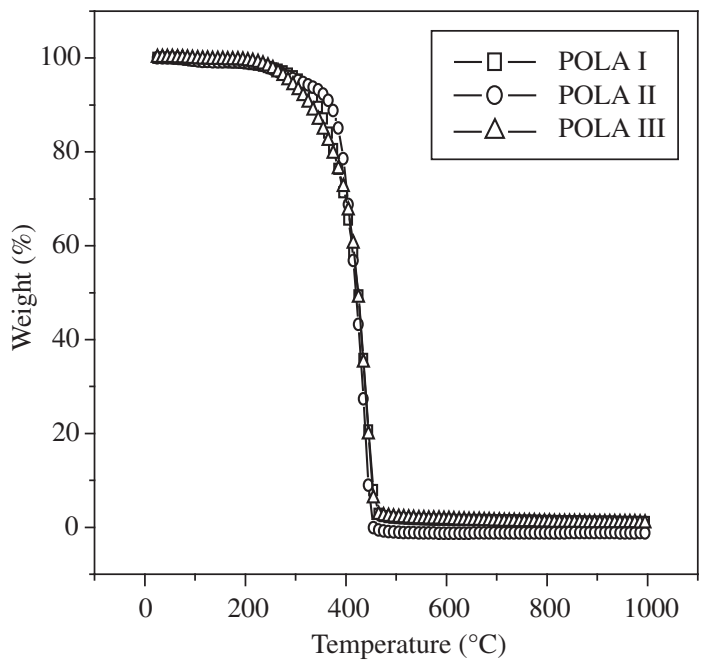

(a)

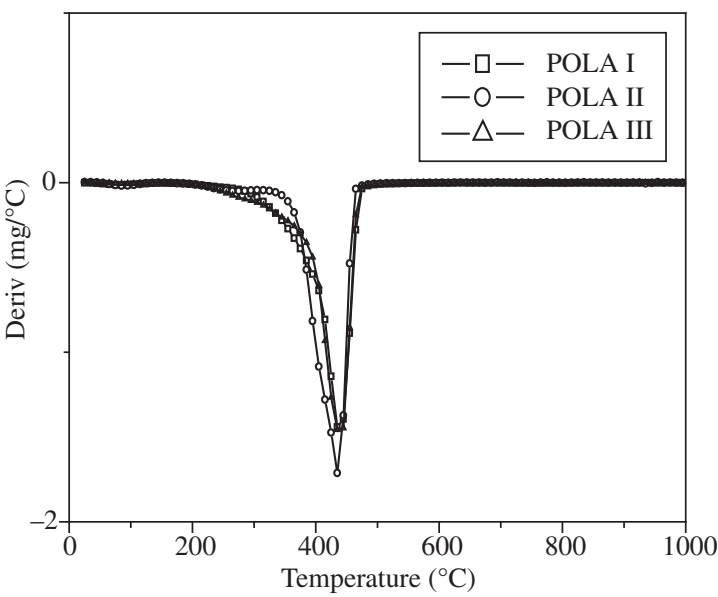

(b)

Figure 6. a) Thermogravimetric Analysis curves; and b) DTG from POLA series.

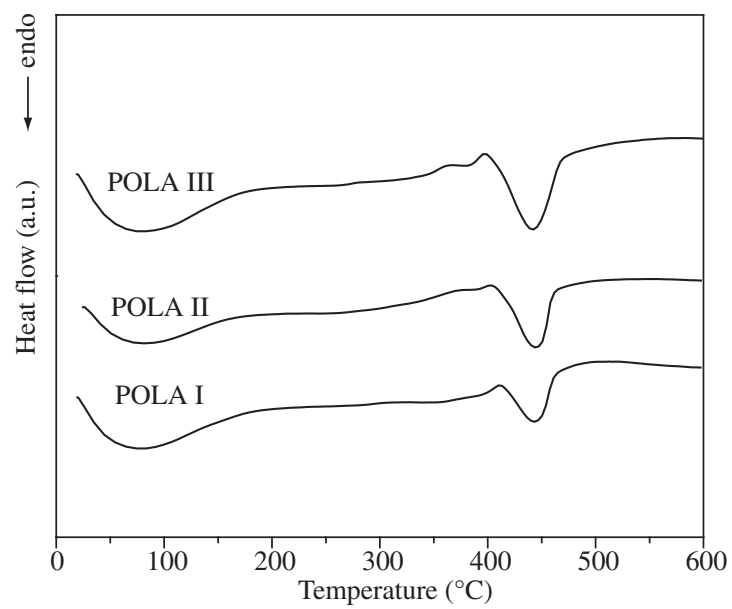

Figure 7. Differential scanning calorimetry curves from POLA series. 


\subsubsection{Scanning Electron Microscopy (SEM)}

The polymers of series POLA had presented surface with roughness details, uniformly distributed in all the extension of the sample, as it can be seen in Figure 8 .

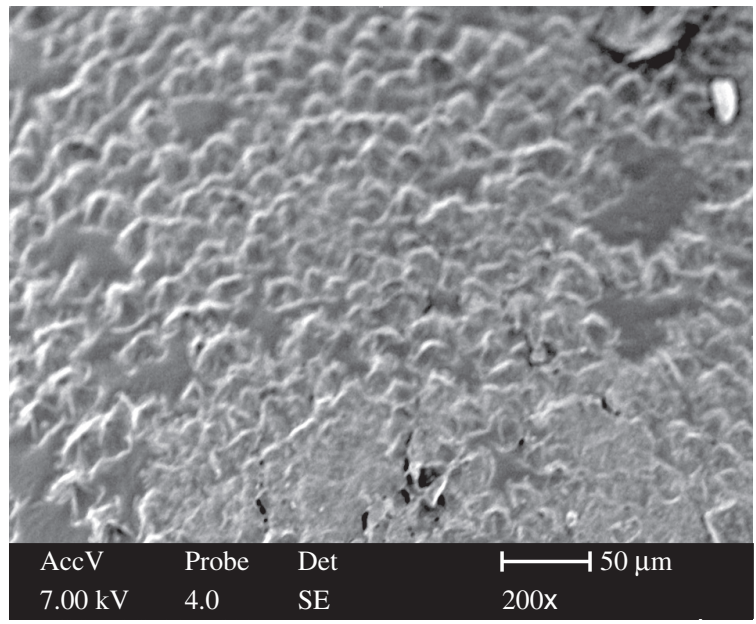

(a)

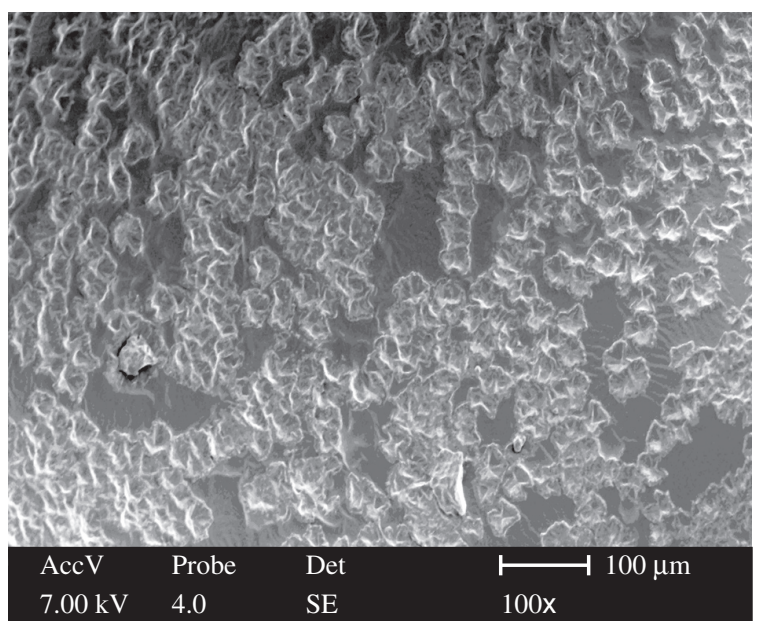

(b)

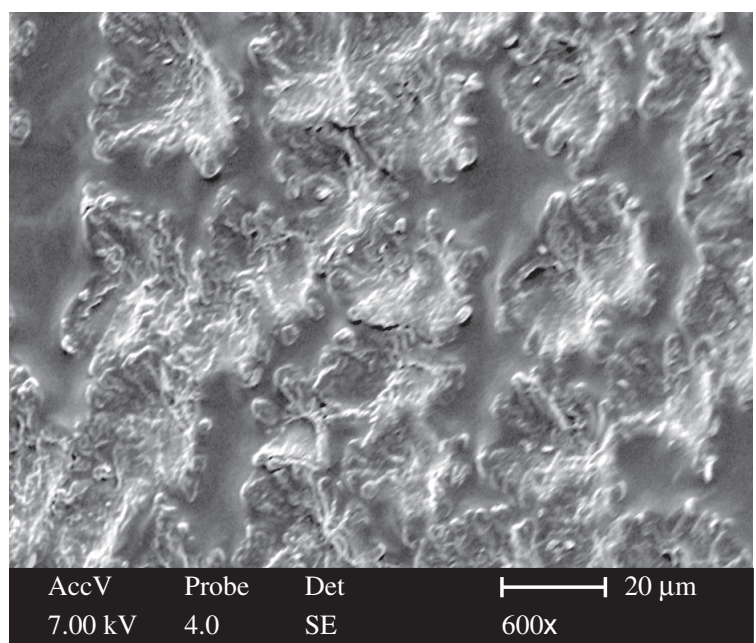

(c)

Figure 8. SEM Micrographs of a) POLA I; b) POLA II; and c) POLA III.

\section{Conclusions}

The bulk polymerization between adipic acid and glycerol proved to be an efficient method for the production of new polyesters, though evidences for the presence of un-reacted - $\mathrm{COOH}$ groups were found for all the polymers prepared in this work. The materials had good mechanical and thermal stability (up to $390{ }^{\circ} \mathrm{C}$ ). DSC and XRD results suggested that these materials are amorphous, although some organization may arise for the samples containing higher amounts of adipic acid.

These features could enable the use of these polyesters as modifiers for thermosets (epoxy resins) or polyurethanes. The use of these materials for the development of new membranes for gas-separation and pervapouration will be also considered and it is going to be a topic of research in our group for the coming years.

\section{Acknowledgments}

The authors acknowledge FAPESB (Fundação de Amparo à Pesquisa do Estado da Bahia) for the financial and technical support given to this work

\section{References}

1. Duarte AP, Borado JC, Ciadade MT. Celulose acetate reverse osmosis membrances. Jornal of Applied Polymer Science. 2007; 103(1):134.

2. Araguren MI, Mosiewicki M, Fernández JB. Natural composites: Polymeric matrices base on vegetable resources. Molecular Crystals and Liquid Crystals. 2006; 448:747.

3. Can E, Wool RP, Kusefoglu S. Soybean and castor oil based monomers: Synthesis and copolymerization with styrene. Journal of Applied Polymer Science. 2006a; 102(3):2433.

4. Can E, Wool RP, Kusefoglu S. Soybean. and castor-oil-based thermosetting polymers: mechanical properties. Journal of Applied Polymer Science. 2006b; 102(3): 1497.

5. Knothe G, Dunn RO, Bagby MO. Biodiesel: The use of vegetable oils and their derivatives as alternative diesel fuels. ACS Symposium Series. 1997; 666:172.

6. Ma FR, Hanna MA. Biodiesel production. Bioressource Technology. 1999; 70(1):1

7. Fukuda H, Kondo A, Noda H. Biodiesel fuel production by transesterification of oils. Journal of Bioscience and Bioengineering. 2001; 92(5):405

8. Biodiesel no Brasil. [homepage on the Internet]. Curitiba: Biodiesel Online ltda; c. 2006-2007 [updated 2007 Nov 25; cited 2006 Aug]. Availabe from: http://www.biodieselbr.com/biodiesel/biodiesel-brasil. $\mathrm{htm}$, accessed on 07/08/2006.

9. Tudo sobre a mamona. [homepage on the Internet]. Curitiba: Biodiesel Online ltda; c. 2006-2007 [updated 2007 Nov 25; cited 2006 Aug]. Availabe from: http://biodieselbr.com/plantas/mamona/index.htm accessed on 14/08/2006.

10 Muniyappa PR, Brammer SC, Noureddini H. Improved conversion of plant oils and animal fats into biodiesel, and co-product. Bioressouce Technology. 1996; 56(1):19.

11. Bucio E, Lara-Estevez JCI, Ruiz-Trevino FA, Acosta-Huerta A. Synthesis and characterization of new polyesters derived from diphenols and aromatic diacids chlorides. Polymer Buletin. 2006; 56(2-3):163.

12. Kiyotsukuri T, Kanaboshi M, Tsutsumi N. Network polyester films from glycerol and dicarboxylic acids. Polymer International. 1994; 33(1):1.

13. Stumbe JF, Brunchmann B. Hyperbranched polyesters based on adipic acid and glycerol. Macromolecular Rapid Communications. 2004; 25(9):921.

14. Polióis. [homepage on the Internet]. Rio de Janeiro: Walter Vilar; c. 20042007 [updated 2007 Nov 25; cited 2006 Mar]. Availabe from:http://www. poliuretanos.com.br/Poliois, accessed on 06/03/2006. 
15. Bryan E. Chemistry and technology of Epoxy Resins. London: Champman \& Hall; 1993. p. 72.

16. Azaroff LV. Elements of X-Ray Cristallography. 1. ed. New York: McGraw-Hill; 1968.

17. Pavia DL, Lampman GM, Kriz GS. Introduction to Spectroscopy. 2. ed. New York: Saunders College Publishing; 1996.

18. Nakanishi K, Solomon PH. Infrared Absorption Spectroscopy. 2. ed. Oakland: Holden-Day; 1977.

19. Zorba T, Chrissafis K, Paraskevopoulos KM, Bikiaris DN. Efefect of molecular weight on thermal degradation mechanism of three poly(alkylene adipate)s: Comparative study. Polymer Degradation and Stability. 2007; 92(2):222.
20. Chrissafis K, Paraskevopoulos KM, Bikiaris DN. Effect of molecular weight on thermal degradation mechanism of the biodegradable polyester poly(ethylene succiante). Thermochimica Acta. 2006; 440(2):166.

21. Aoyagi Y, Yamashita K, Doi Y. Termal degradation of poly[(R)-3hydroxybutyrate], poly[epsilon-caprolactone], and poly[(S)-lactide]. Polymer Degradation and Stability. 2002; 76(1):53.

22. Arvanitoyannis I, Nakayama A, Kawasaki N, Yamamoto N. Novel starshaped polylactide with glycerol using stannous octoate or tetraphenyl tin as catalyst.1.1 sysnthesis, characterization and study of their biodegradability. Polymer. 1995; 36(15):2947. 